\title{
Intraply fracture of fiber-reinforced composites: Microscopic mechanisms and modeling
}

\author{
Luis Pablo Canal ${ }^{\mathrm{a}}$, Carlos González ${ }^{\mathrm{a}, \mathrm{b}}$, Javier Segurado ${ }^{\mathrm{a}, \mathrm{b}}$, Javier LLorca ${ }^{\mathrm{a}, \mathrm{b}, *}$
}

\begin{abstract}
A B S T R A C T
The fracture behavior parallel to the fibers of an E-glass/epoxy unidirectional laminate was studied by means of three-point tests on notched beams. Selected tests were carried out within a scanning electron microscope to ascertain the damage and fracture micromechanisms upon loading. The mechanical behavior of the notched beam was simulated within the framework of the embedded cell model, in which the actual composite microstructure was resolved in front of the notch tip. In addition, matrix and interface properties were independently measured in situ using a nanoindentor. The numerical simulations very accurately predicted the macroscopic response of the composite as well as the damage development and crack growth in front of the notch tip, demonstrating the ability of the embedded cell approach to simulate the fracture behavior of heterogeneous materials. Finally, this methodology was exploited to ascertain the influence of matrix and interface properties on the intraply toughness.
\end{abstract}

\section{Introduction}

Current advances to carry out high fidelity simulations of the mechanical behavior of fiber-reinforced polymers are based on novel multiscale modeling strategies, which take advantage of the fact that composite structures are made up of laminates obtained by stacking individual plies with different fiber orientation [1]. This leads to three different entities (ply, laminate and component) whose mechanical behavior is characterized by three different length scales, namely fiber diameter $(5-25 \mu \mathrm{m})$, depending on the reinforcement material), ply thickness $(100-300 \mu \mathrm{m})$ and laminate thickness (several $\mathrm{mm}$ ). This clear separation of length scales is very useful for carrying out multiscale modeling by computing the properties of one entity (e.g. individual plies) at the relevant length scale, homogenizing the results into a constitutive model, and passing this information to the simulations at the next length scale to determine the mechanical behavior of the larger entity (e.g. laminate). Thus, multiscale modeling is carried out through the transfer of information between different length scales rather than by coupling different simulation techniques.

The first step in this simulation ladder begins with the determination of the micromechanisms of deformation and fracture within the ply and the relevant fiber, matrix and interface properties. This data, together with information about the fiber volume fraction and spatial distribution, is used to determine the ply mechanical properties which are used in the simulations at the next length scale. Basically, the ply information required by the mesoscale models includes the elastic ply constants, the failure surface in the stress space and the toughness associated with the different fracture modes (matrix cracking and shear yielding, fiber buckling and fiber tensile fracture) [2-4]. Ply elastic constants are accurately predicted by means of standard homogenization models [5], while the ply strength under different stress states can be obtained from experimentally-validated phenomenological models [6-8] or by means of computational micromechanics. This latter methodology is based on the numerical simulation of the mechanical behavior of a representative volume element (RVE) of the composites microstructure using periodic boundary conditions to eliminate surface effects [9-14] and it has demonstrated its ability to account for complex non-linear deformation and damage mechanisms as well as multiaxial stress states.

Thus, although various valid procedures are available to determine the ply stiffness and strength, the values of the toughness associated with each ply fracture mode are more difficult to estimate. While novel experimental techniques are under development $[15,16]$, another interesting approach is the application of computational micromechanics. Simulations have to account for the localization of damage and the propagation of a crack from the tip of a sharp crack and this is incompatible with the analysis of an RVE under periodic boundary conditions. Instead, simulations can be carried out within the framework of an embedded cell model $[17,18]$ in which the full details of the composite microstructure are resolved in the fracture region. The remaining ply 
material is represented as a homogeneous, transversally-isotropic elastic solid whose behavior is given by any suitable homogenization model. This methodology, which was initially applied to determine the toughness of uniaxially reinforced $\mathrm{Ti} / \mathrm{SiC}$ composite plies $[17,18]$ and was recently used in braided polymer-matrix composites [19], is used in this investigation to determine the toughness of uniaxially-reinforced glass-fiber polymer-matrix composite when the crack propagates parallel to the fibers. To this end, the actual deformation and failure mechanisms were carefully ascertained by means of in situ mechanical testing in a scanning electron microscope and the in situ matrix and interface properties were measured by means of nanoindentation or estimated. This information was used to predict the ply toughness by using an embedded cell approach and compared with experimental results in terms of the actual crack path throughout the microstructure and the overall load-displacement behavior. Finally, a parametrical study was carried out to ascertain the influence of matrix and interface properties on the ply toughness.

\section{Material and experimental techniques}

\subsection{Material and mechanical characterization}

Panels of $350 \times 300 \times 2 \mathrm{~mm}^{3}$ following the $[0]_{10}$ stacking sequence were manufactured in an autoclave from unidirectional prepregs made from E-glass fibers pre-impregnated with MTM57 epoxy resin (Advanced Composite Group, UK). They were heated at $3{ }^{\circ} \mathrm{C} / \mathrm{min}$ and consolidated at $120^{\circ} \mathrm{C}$ and $0.64 \mathrm{MPa}$ for $30 \mathrm{~min}$. Afterwards, they were cooled at $3{ }^{\circ} \mathrm{C} / \mathrm{min}$ and the pressure was released at $80^{\circ} \mathrm{C}$. After manufacturing, the panels were inspected by ultrasounds to ensure that they were free of delaminations or other defects. The fiber volume fraction was $54 \%$ as determined from the thickness and density of the laminate and its constituents.

Beams with a rectangular cross-section of $2.8 \mathrm{~mm}$ (depth, $D) \times 2 \mathrm{~mm}$ (thickness, $t$ ) were mechanized from the panel with the fibers perpendicular to the beam axis. A notch was machined in the central section of the beam with a thin diamond wire. The initial notch depth $\left(a_{0}\right)$ was $0.5 D$ and the notch tip radius was $\approx 130 \mu \mathrm{m}$. The fracture behavior of the composite panel was determined by means of three-point bend tests on notched beams with $11.2 \mathrm{~mm}$ of loading span $S$ (Fig. 1). They were carried out in an Instron 5543A electromechanical testing machine under stroke control at a constant cross-head speed of $100 \mu \mathrm{m} / \mathrm{min}$. The applied load $(P)$ was continuously recorded during the tests with a load cell of $100 \mathrm{~N}$. In addition, the displacement of the loading point $(\delta)$ and the crack mouth opening displacement (CMOD) were measured by means of digital image correlation (VicSNAP, Correlated Solutions, Inc.). To this end, one of the beam lateral surfaces was scratched with SiC paper of 250 grit to create a grey speckle pattern which could be tracked by the analysis software.

Additional three-point bend tests of notched beams with the same dimensions were carried out inside a scanning electron microscope (Zeiss EVO MA-15) to ascertain the dominant deformation and

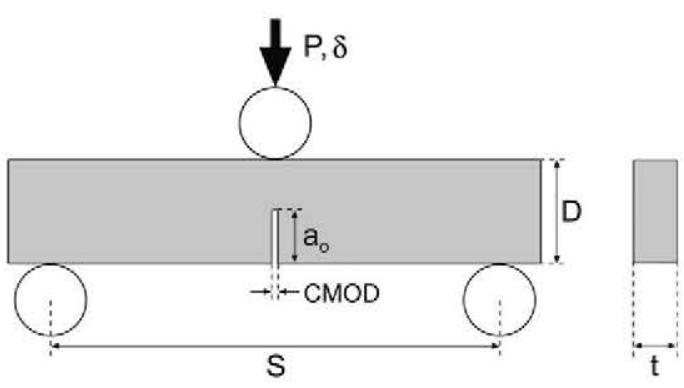

Fig. 1. Schematic of the three-point bending tests on notched beams.

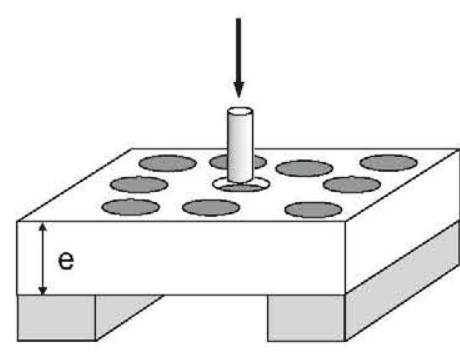

Fig. 2. Schematic of the push-out test.

damage mechanisms during fracture. To this end, the notched beams were sputtered with $\mathrm{Au}-\mathrm{Pd}$, and the bending test fixture was set up in a micro-electromechanical testing machine (Kammarth \& Weiss Tensile/Compression Stage) which can be fitted in the scanning electron microscope. The actuator of the testing machine was stopped at regular intervals of $5 \mu \mathrm{m}$ and micrographs of the microstructure in front of the notch tip and along the crack path were obtained at different magnifications $(50 \times, 85 \times, 250 \times$ and $500 \times)$.

\subsection{Determination of matrix and interface properties}

The shear strength of the fiber/matrix interface was determined by means of push-out tests [20-23]. To this end, slices transversal to the fibers were cut from the composite panel and thinned by polishing up to a thickness $e \approx 20-30 \mu \mathrm{m}$. They were placed on a metallic support with a groove of $\approx 50 \mu \mathrm{m}$ in width (Fig. 2) and mounted on a MTS Nanoindenter XP equipped with a flat-punch tip of $10 \mu \mathrm{m}$ in diameter. Individual fibers were loaded with the nanoindentor tip at a displacement rate of $50 \mathrm{~nm} / \mathrm{s}$. The lamella were thin enough to allow for complete decohesion over the fiber/matrix interface and the fiber was pushed out from the lamella (Fig. 2).

The matrix elastic modulus and the flow stress in compression were measured by means of instrumented nanoindentation tests of the matrix into resin pockets between the fibers on a polished section of the composite, following a recently developed methodology [24]. Five nanoindentation tests were performed with a Berkovich indenter tip. Special care was taken to place the nanoindentations sufficiently far away from the fibers to avoid their constraining effect which led to a marked stiffening (easy to detect) [1]. The load was applied at a constant rate of $0.2 \mu \mathrm{m} / \mathrm{s}$. It was held for $10 \mathrm{~s}$ to reduce creep deformation upon unloading, which could induce inaccurate predictions of the material properties, and the indenter was lifted off the surface, leading to an elastic unloading branch.

\section{Experimental results}

\subsection{Fracture tests and fracture mechanisms}

The $P-C M O D$ curves of five three-point bend tests on notched beams of unidirectional $[0]_{14}$ E-glass/MTM57 composites are plotted in Fig. 3. The behavior was approximately linear up to the maximum load and it was followed by a sudden drop in load down to 0.6-0.7P $P_{\text {max }}$. Further deformation led to a long tail in which the load was progressively reduced as the crack propagated across the beam's central section. The test ended with the splitting of the beam in two halves. From the fracture viewpoint, the behavior of the unidirectional composite in the plane perpendicular to the fibers can be characterized by the nominal fracture toughness, $K_{I c}$, and the fracture energy, $G_{I c}$, which are shown in Table 1 . The former can obtained from the maximum load and the initial notch length according to:

$K_{l c}=\frac{3 P_{\max } S}{2 t D^{3 / 2}} \kappa\left(a_{0} / D\right)$ 


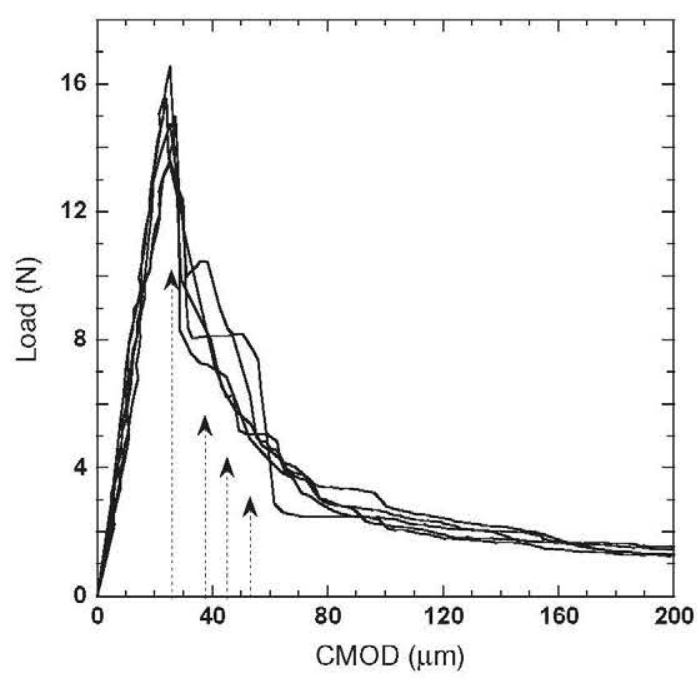

Fig. 3. Load-CMOD curves of the fracture tests in E-glass/MTM57 unidirectional lamina. The four vertical arrows indicate the CMOD values corresponding to the micrographs from Fig. 5 a to d.

where $\kappa\left(a_{0} / D\right)$ is a non-dimensional shape function which depends on the specimen geometry [25]. This expression was derived for isotropic solids, but it can be applied in the case because the lamina is isotropic in the plane perpendicular to the fibers. The latter is given by the total energy spent to fracture the specimen divided by the area of the central ligament. Mathematically,

$G_{I c}=\frac{\int_{0}^{\infty} P d \delta}{\left(D-a_{0}\right) t}$

The deformation and fracture micromechanisms associated with the $P-C M O D$ curves in Fig. 3 were identified by means of the mechanical tests inside the SEM and are shown in Fig. 4. No damage was detected on the specimen surface before the maximum load was achieved (Fig. $4 \mathrm{a})$. Shortly afterwards $(C M O D \approx 37 \mu \mathrm{m})$, damage developed from the notch tip as a result of fiber-matrix decohesion in the fibers located in front of the notch tip, leading to a marked reduction in the load carried by the notched beam (Fig. 4b). Crack propagation from the notch tip was discontinuous and it was formed by a number of decohered interfaces connected by matrix ligaments (Fig. 4c). As the applied displacement increased, matrix ligaments were broken and a continuous crack grew from the notch. The crack path was not straight at the microscopic level but presented some tortuosity as a result of the random fiber distribution in the composite (Fig. 4d). The process was replicated in a self-similar fashion as the crack grew until the complete failure of the specimen.

Observation of the microscopic damage process at higher magnification (Fig. 5) showed that interface decohesion started at the equator of the fibers and propagated towards the poles. The propagation of the interface crack was accompanied by the growth of an interfacial void and by the shear failure of the matrix between debonded fibers, indicating that the microscopic fracture processed involved significant non-linear deformation of the epoxy matrix.

Table 1

Fracture properties of the E-glass/MTM57 lamina parallel to the fibers.

\begin{tabular}{ll}
\hline$K_{l c}(\mathrm{MPa} \sqrt{\mathrm{m}})$ & $G_{l c}\left(\mathrm{~J} / \mathrm{m}^{2}\right)$ \\
\hline $1.8 \pm 0.2$ & $400 \pm 50$ \\
\hline
\end{tabular}

\subsection{Interface properties}

A typical load-fiber displacement curve obtained in a push-out test is plotted in Fig. 6a. All curves always presented the same features with three different regions. The initial linear region corresponds to the elastic bending of the thin composite slice between the supports, followed by the elastic deformation of the fiber under the action of the flat punch. This second zone ends abruptly with the fracture of the interface as the fiber is pushed out from the slice. After some sliding, the flat punch displacement was reversed and the load decreased to zero following a similar path. After the tests, the specimens were inspected in the scanning electron microscope. The upper and lower surfaces of the thin slices were observed to check that the pushed fibers were completely debonded from the matrix (Fig. 6b and c). Furthermore, the thickness of the slice and the diameter of the tested fibers were accurately measured during the microscopic inspection of the tested specimen.

Fibers covering a wide range of diameters (between 15 and $30 \mu \mathrm{m}$ ) and either closely packed among other fibers or isolated in the matrix were tested. For each fiber, the interface shear strength, $S$ was computed from the maximum load carried by the fiber in the push-out, $F_{\max }$, test as

$S=\frac{F_{\max }}{2 \pi r e}$

where $r$ and $e$ stand for the fiber radius and the slice thickness, respectively. The average value of the interface shear strength is shown in Table 2 and is in good agreement with previous results obtained in this material by means of the push-in test [26].

The in situ fracture tests (Figs. 4 and 5) showed that interface decohesion was often triggered by normal rather than shear interface stresses, and push-out tests only provided values for shear strength. The failure criteria for a glass fiber/epoxy interface under combined normal and shear stresses was studied by Ogihara and Koyanagi [27] by means of cruciform specimens with one fiber in the center. They found that normal interface strength, $N$, was equal to $2 S / 3$ and this value was used in the numerical simulations presented below.

\subsection{Matrix properties}

The imprint due to a Berkovich tip in a matrix pocket is shown in Fig. $7 \mathrm{a}$ and the corresponding load-displacement curve is plotted in Fig. 7b. From this test, it is possible to determine the matrix hardness, $H_{m}$, and elastic modulus, $E_{m}$, of the material according to [28]

$H_{m}=\frac{F_{\max }}{A} \quad \frac{1-v_{m}^{2}}{E_{m}}=\frac{2 \sqrt{A}}{S_{\text {ind }} \sqrt{\pi}}-\frac{1-v_{i}^{2}}{E_{i}}$

where $F_{\max }$ and $A$ stand for the maximum indentation load and the actual contact area, respectively, $S_{\text {ind }}$ the initial elastic stiffness upon unloading, $E_{i}$ and $v_{i}$ the elastic constants of the indentor tip, and $v_{m}$ the Poisson's ratio of the matrix $(0.35$ according to the manufacturer). Determining the actual contact area is, however, rather complex in the case of polymers because it cannot be estimated from the residual imprint after indentation (Fig. 7a) due to the relaxation phenomena induced by the viscoelastic behavior of the polymer. In addition, pile-up or sink-in of the material on the edges of the imprint modify the actual contact area and they depend on the constitutive equation of the material. Cheng and Cheng [29] carried out a parametrical study to determine the actual contact area during indentation of elasto-plastic materials as a function of the fraction of elastic energy during indentation. ${ }^{1}$ With this information, it was

\footnotetext{
1 The elastic energy stored during indentation is given by area under the unloading curve in Fig. $7 \mathrm{~b}$, while the total energy is the area under the loading curve. The difference between them is the area enclosed between the loading and unloading curves and indicates the energy dissipated by plastic deformation during indentation.
} 



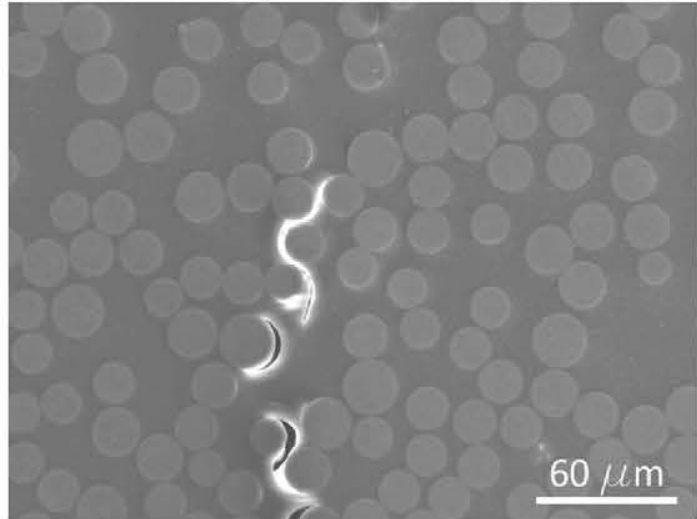

Fig. 5. Detailed of the damage processes by interface decohesion and matrix failure in front of the notch tip.

possible to obtain the compressive flow stress from the hardness but their results were limited to materials in which the flow stress was pressure-independent.

Rodríguez et al. [24] recently extended the work of [29] to pressure-sensitive elasto-plastic materials in which the flow stress follows the Drucker-Prager yield criterion. Neglecting rate effects, this approach can be used to predict the compressive flow stress and the elastic modulus of the epoxy resin from the hardness, the elastic stiffness and the fraction of the elastic energy in the indentation test and the parameter $\alpha$ which defines the pressuresensitivity of the flow stress. The value of $\alpha=0.13$ was determined previously for the MTM57 epoxy from the deviation of the fracture plane from the maximum shear stress plane in composite samples subjected to uniaxial compression perpendicular to the fibers
Table 2

Fiber, matrix and interface properties of E-glass/MTM57 composite. Fiber elastic $\left(E_{f}\right.$ and $v_{f}$ ) constants were obtained from [40].

\begin{tabular}{lllllllll}
\hline $\begin{array}{l}E_{f} \\
(\mathrm{GPa})\end{array}$ & $v_{f}$ & $\begin{array}{l}E_{m} \\
(\mathrm{GPa})\end{array}$ & $\begin{array}{l}v_{m} \\
(\mathrm{MPa})\end{array}$ & $\begin{array}{l}\sigma_{m}^{y c} \\
(\mathrm{MPa})\end{array}$ & $\alpha$ & $\begin{array}{l}\sigma_{m}^{y t} \\
(\mathrm{MPa})\end{array}$ & $\begin{array}{l}S \\
(\mathrm{MPa})\end{array}$ & $\begin{array}{l}N \\
(\mathrm{MPa})\end{array}$ \\
\hline 74 & 0.2 & 3.5 & 0.35 & 105 & 0.13 & 75 & $75 \pm 15$ & 50 \\
\hline
\end{tabular}

under the assumption that the shear bands in the matrix and in the composite had the same orientation $[30,6]$. It was in agreement with values reported for other glassy polymers $(0.08 \leqslant \alpha \leqslant 0.23)$ [6,31].

The hardness, elastic stiffness and fraction of elastic energy in the nanoindentation tests on resin pockets in the composite were, respectively, $200 \mathrm{MPa}, 56.9 \mathrm{kN} / \mathrm{m}$, and 0.42 . From these values, it was possible [24] to determine the compressive yield strength, $\sigma_{m}^{y c}$ and the elastic modulus, $E_{m}$ of the MTM57 epoxy resin, which are shown in Table 2 . These values were close to those provided by the manufacturer ( $120 \mathrm{MPa}$ and $3.35 \mathrm{GPa}$ ).

\section{Computational model}

The virtual test to compute the toughness of the composite lamina parallel to fibers was carried out by simulating the three-point bend test of the notched beam by means of an embedded cell model, following the strategy developed in [17] (Fig. 8). The whole notched beam is included in the numerical model but it is divided in two regions. The actual microstructure was represented in front of the notch tip, where all the fracture processes occur (Fig. 4), while the remainder of the beam was assumed to be a homogenous solid. The displacement field was continuous across the interface between both regions.
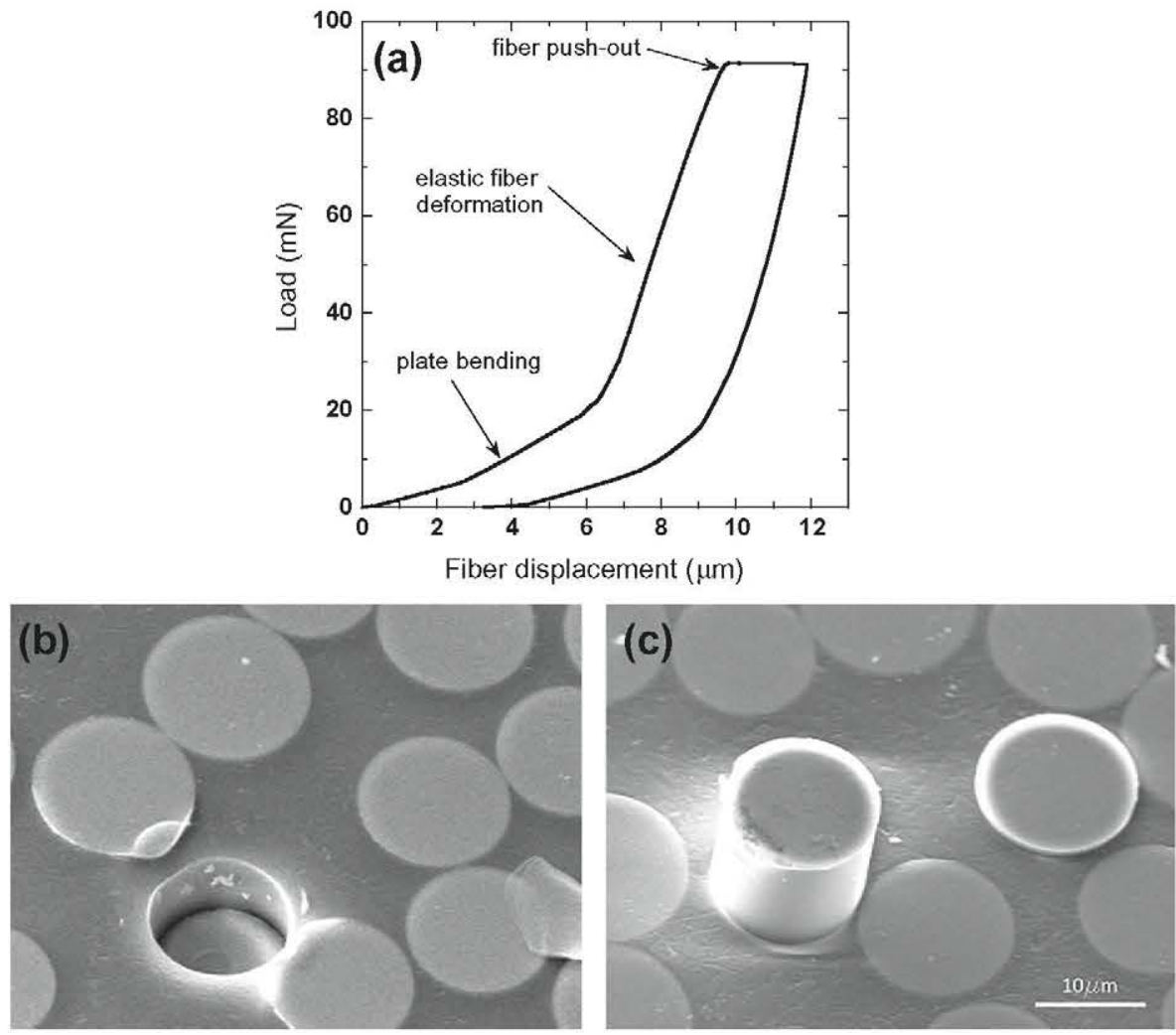

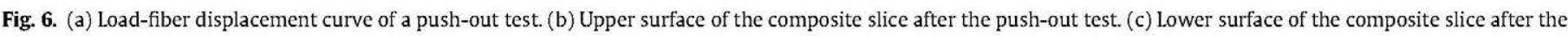
push-out test. 

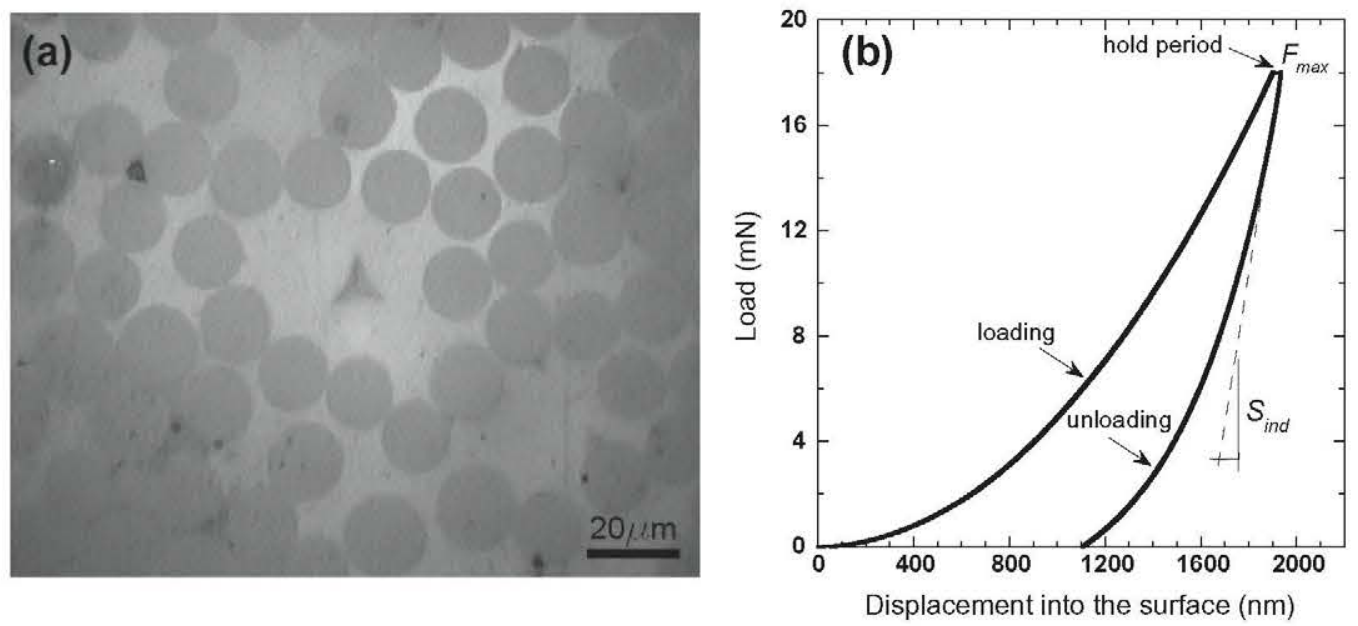

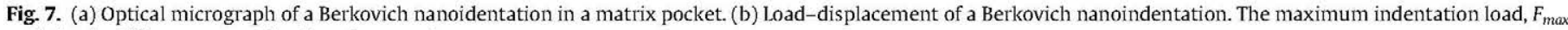
and elastic stiffness upon unloading, $S_{\text {ind }}$, are shown.

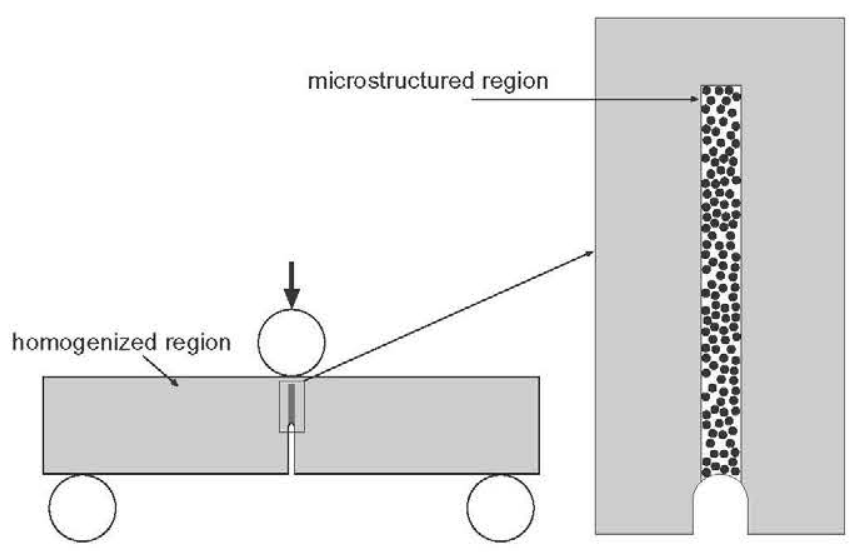

Fig. 8. Schematic of the embedded cell model to simulate the three-point bend test on a notched beam.

The homogenized material was assumed to behave as a linear elastic, isotropic solid whose elastic constants in the beam plane $\left(E_{h}=11 \mathrm{GPa}\right.$ and $v_{h}=0.3$ ) were computed from the matrix and fiber elastic properties (Table 2) and the fiber volume fraction (54\%) by means of the Mori-Tanaka approximation [32]. In front of the notch tip, the lamina cross-section was represented by a random, homogeneous dispersion of monosized circular glass fibers embedded in an epoxy matrix. The fiber volume fraction was $54 \%$, as in the homogenized region. Glass fibers were assumed to behave as linear elastic, isotropic solids, whose elastic constants are given in Table 2. The epoxy matrix was modeled as an isotropic, elastoplastic solid. The matrix elastic constants are also found in Table 2 , while plastic deformation and fracture was included by means of a continuum plasticity-damage model developed by Lubliner et al. [33,34], which takes into account the pressure-sensitivity of the epoxy flow stress under compression and its brittle behavior in tension. The yield surface of the epoxy is expressed by a modification of the Drucker-Prager yield function according to

$\phi\left(I_{1}, J_{2}, \sigma_{l}, \beta, \alpha\right)=\frac{1}{1-\alpha}\left(\sqrt{\frac{3 J_{2}}{2}}+\frac{I_{1}}{3} \alpha+\beta\left\langle\sigma_{l}\right\rangle\right)-\sigma_{m}^{y c}=0$

where $I_{1}$ stands for the first invariant of the stress tensor, $J_{2}$ is the second invariant of the deviatoric stress tensor, $\alpha$ the pressure-sensitivity parameter of the Drucker-Prager yield criterion, $\sigma_{f}$ the maximum principal stress, \langle\rangle the Macaulay brackets (which return the
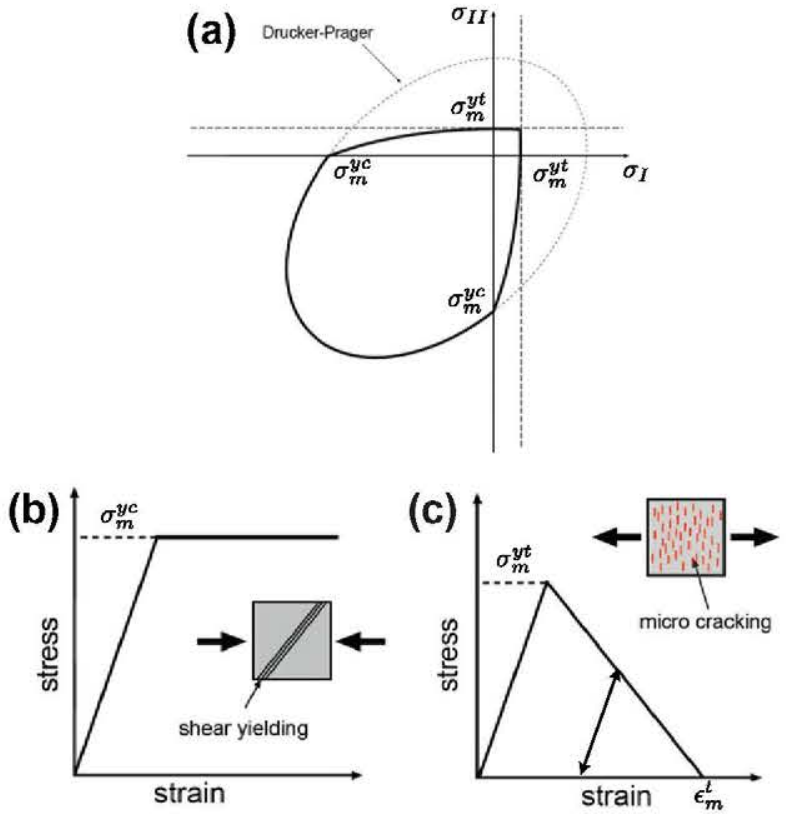

Fig. 9. (a) Yield surface of the epoxy matrix under plane stress conditions. (b) Postyield behavior in compression and shear. (c) Post-yield behavior in tension.

argument if positive and zero otherwise), and $\beta$ a parameter function of the tensile $\left(\sigma_{m}^{y t}\right)$ and compressive $\left(\sigma_{m}^{y c}\right)$ yield stress according to

$\beta=\frac{\sigma_{m}^{y c}}{\sigma_{m}^{y t}}(1-\alpha)-(1+\alpha)$

The corresponding yield surface under plane stress conditions is plotted in Fig. 9 in the stress space of the principal stresses. Under compression, the matrix follows the standard Drucker-Prager yield criterion, which has been validated experimentally for glassy polymers [6,31]. In tension, however, yielding is mainly controlled by the maximum principal stress. In addition, the post-yielding behavior was different in compression and tension, in agreement with the experimental behavior of epoxy resins. Plastic deformation at constant flow stress occurred in compression and shear after yielding, leading to final failure by the formation of a shear band (Fig. 9b). Conversely, the brittle behavior in tension due to microcracking was accounted for by a linear softening law. The energy dissipated 
by unit volume during tensile cracking was controlled by the failure strain, $\epsilon_{m}^{t}$.

It is well known that the numerical implementation of continuum damage models with softening leads to mesh sensitivity problems, with the energy dissipated decreasing with element size. Mesh regularization can be achieved by means of the crack band model [35] in which the input is the matrix fracture energy, $G_{m}$, which is related to the stress-strain relationship in tension (Fig. 9c) according to

$G_{m}=\frac{1}{2} \sigma_{m}^{y t} \epsilon_{m}^{t} l_{c h}$

where $l_{c h}$ is the characteristic length of the finite element. For the second-order, triangular elements used for the matrix discretization, $l_{c h}$ is equal to half of the height of the triangular element [36]. More detailed descriptions of the constitutive model for the epoxy and its numerical implementation in a finite element code can be found in $[33,36]$.

All the material parameters in the constitutive equation of the matrix were experimentally determined (and are shown in Table 2) with exception of the matrix yield stress in tension and the associated fracture energy. The push-in tests to measure the fiber/matrix interfacial strength provided, however, a lower bound for the matrix tensile because there was no evidence of tensile fracture in the matrix around the fibers when the shear stress in the interface was $75 \mathrm{MPa}$. If the matrix could withstand this shear stress, its tensile strength, $\sigma_{m}^{y t}$ should be at least $75 \mathrm{MPa}$. This value coincides with the matrix tensile strength supplied by the manufacturer and was used in the simulations. Regarding to the matrix fracture energy, no experimental data was available and $G_{m}=100 \mathrm{~J} / \mathrm{m}^{2}$ was chosen, which is a sensible value for epoxy resins [37] and is in agreement with recent estimations of the fracture energy of MTM57 resin by X-ray microtomography [38].

The fiber-matrix interface was modeled as a cohesive crack, whose mechanical behavior was expressed in terms of a bilinear traction-separation law which relates the displacement jump across the interface (defined by normal and tangential components, $\delta_{n}$ and $\delta_{s}$, respectively) with the traction vector acting on it (defined by the normal and tangential components, $t_{n}$ and $t_{s}$ ) [39]. The initial response was linear with an elastic stiffness of $K=10^{8} \mathrm{GPa} / \mathrm{m}$, which was large enough to ensure the displacement continuity at the interface and to avoid any modification of the stress fields around the fibers in the absence of damage. The linear behavior ends at the onset of damage, which is dictated by a maximum stress criterion expressed mathematically as

$\max \left\{\frac{\left\langle t_{n}\right\rangle}{N}, \frac{t_{s}}{S}\right\}=1$

where $N$ and $S$ stand for interface strength in tension and shear, respectively (Table 2 ). Once the damage begins, the stress transferred through the crack is reduced depending on the interface damage parameter $d$, which evolves from 0 (in the absence of damage) to 1 (no stresses transmitted across the interface). The corresponding traction-separation law is expressed by,

$$
\begin{aligned}
& t_{n}=(1-d) K \delta_{n} \text { if } \delta_{n}>0 \\
& t_{n}=K \delta_{n} \quad \text { if } \quad \delta_{n} \leqslant 0 \\
& t_{s}=(1-d) K \delta_{s}
\end{aligned}
$$

The mechanical response of the interface is controlled by the nor$\mathrm{mal}(N)$ and shear $(S)$ interface strength and by the energy necessary to completely break the interface, $G_{\text {int }}$ (which is independent of the loading path in this model). The interface fracture energy could not be measured experimentally and it was taken as $150 \mathrm{~J} / \mathrm{m}^{2}$, following the experimental results obtained by Zhou et al. [22] on E-glass/ epoxy composites. More details about the cohesive crack model implementation can be found in $[39,36]$.
Fibers and matrix, as well as the homogenized material, were discretized with 6-node isoparametric modified triangles (CPE6M in [36]) with integration at three Gauss points. Linear interface elements ( $\mathrm{COH} 2 \mathrm{D} 4$ in [36]) were included at the fiber-matrix interface. Simulations were carried out under plane strain conditions using Abaqus/Standard and within the framework of the finite deformations theory with the initial unstressed state as reference.

\section{Numerical results and discussion}

\subsection{Comparison with experiments}

The three-point bend test of the notched beam was simulated using the embedded cell model presented above. The computed

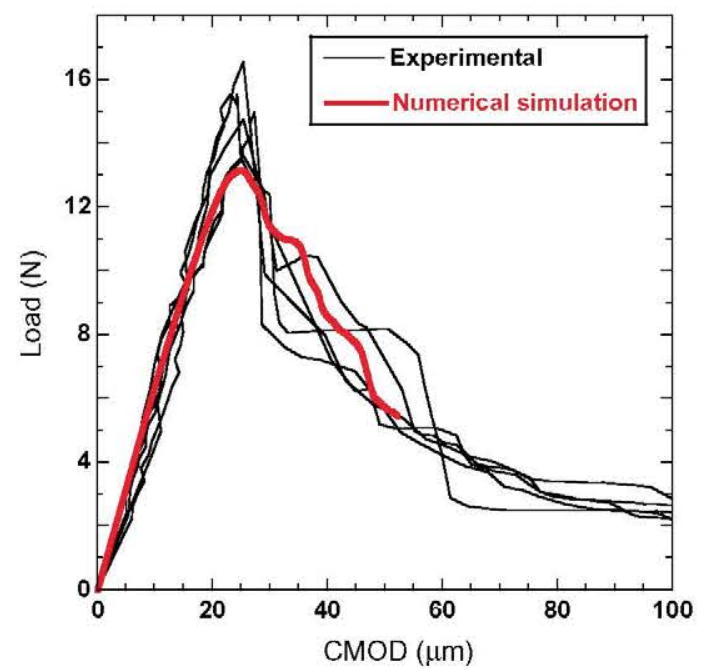

Fig. 10. Experimental and simulated load-CMOD curves of the notched beam subjected to three-point bending.

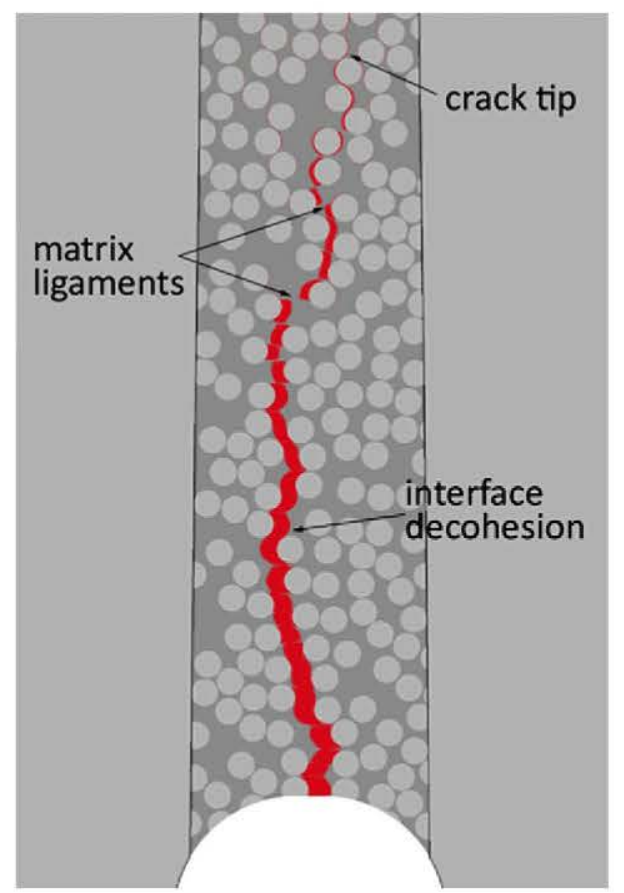

Fig. 11. Detail of the damage micromechanisms leading to crack propagation according to the numerical model. The crack path is shown in red. (For interpretation of the references to color in this figure legend, the reader is referred to the web version of this article.) 

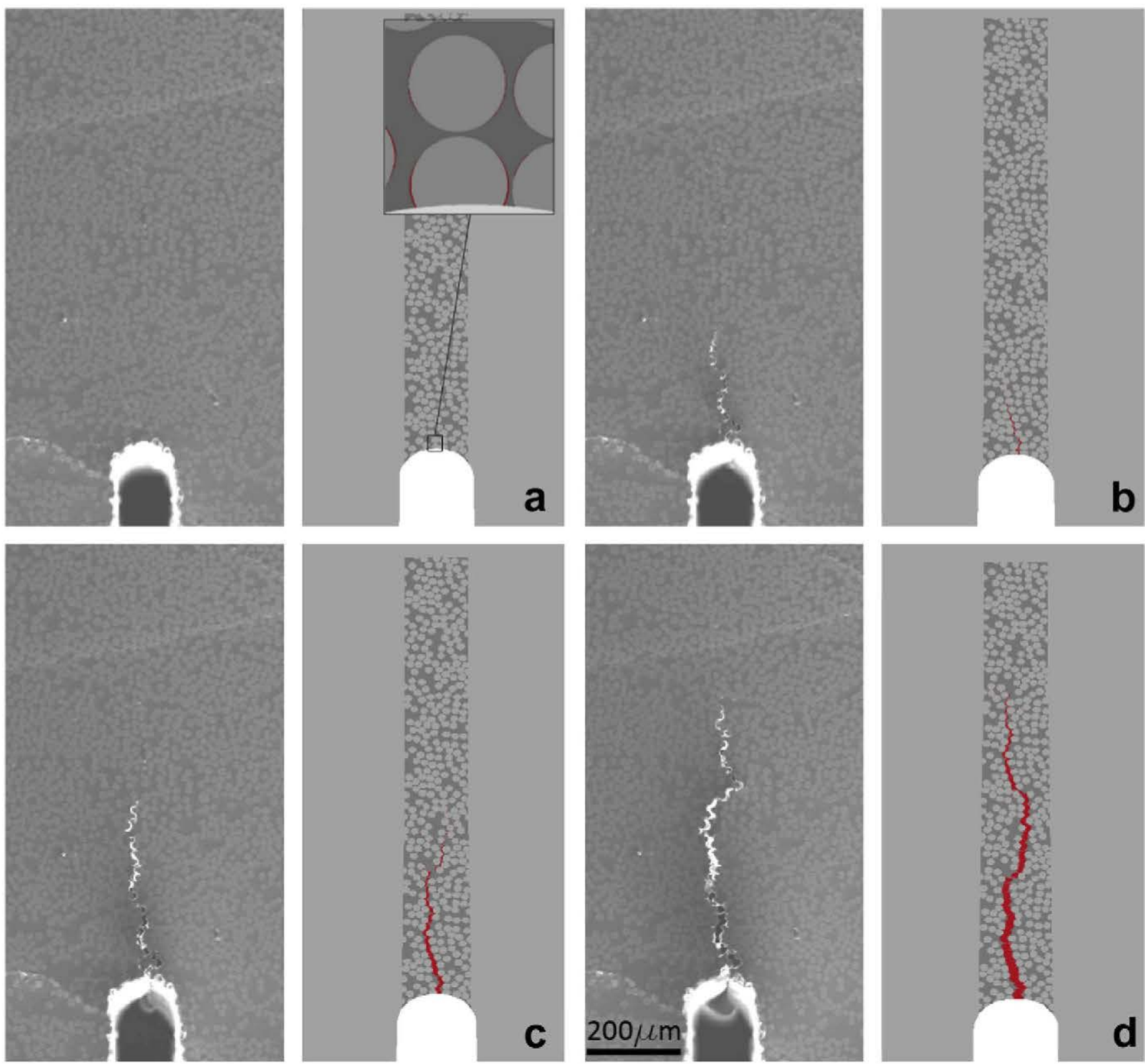

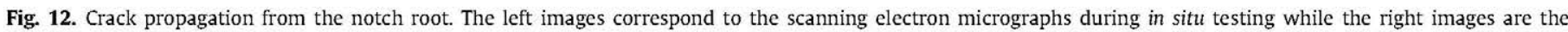

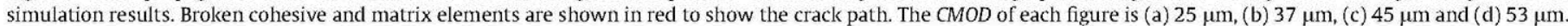
(For interpretation of the references to colour in this figure legend, the reader is referred to the web version of this article.)

load-CMOD curve is plotted in Fig. 10 together with the experimental results. The numerical model accurately reproduced the experimental behavior including the elastic stiffness of the beam, the $C M O D$ at maximum load and the tail of the curve. The maximum load was slightly underestimated (around 5\%) although it was within the experimental scatter.

In addition to the macroscopic response, the model was able to reproduce the actual deformation and failure mechanisms at the microscopic scale. This is shown in Fig. 11, where the crack path throughout the microstructure is plotted in red. As in the scanning electron micrographs (Fig. 5), damage began by interface decohesion at the equator of the fibers. Cracks propagated along the fiber-matrix interface and voids grew by interface separation. A continuous crack was finally developed by the coalescence of the interfacial voids and the fracture of the matrix ligaments between voids.
The numerical simulations also very precisely captured the evolution of the crack propagation with the load. This is shown in Fig. 12, where a sequence of scanning electron micrographs for different values of the $C M O D$ is plotted together with the numerical results for different values of the $C M O D$. Broken interface and matrix elements are colored in red in the numerical simulations to show the meandering crack path, whose tortuosity was controlled by the spatial distribution of the fibers. The numerical model shows that damage began by interface decohesion in the fibers just in front of the notch tip (see inset of Fig. 12a) and the crack length in the actual test and in the simulations was very similar at different loading stages.

\subsection{Parameters controlling the ply toughness}

The accuracy of the embedded cell model to predict macroscopic response and microscopic failure mechanisms makes this 

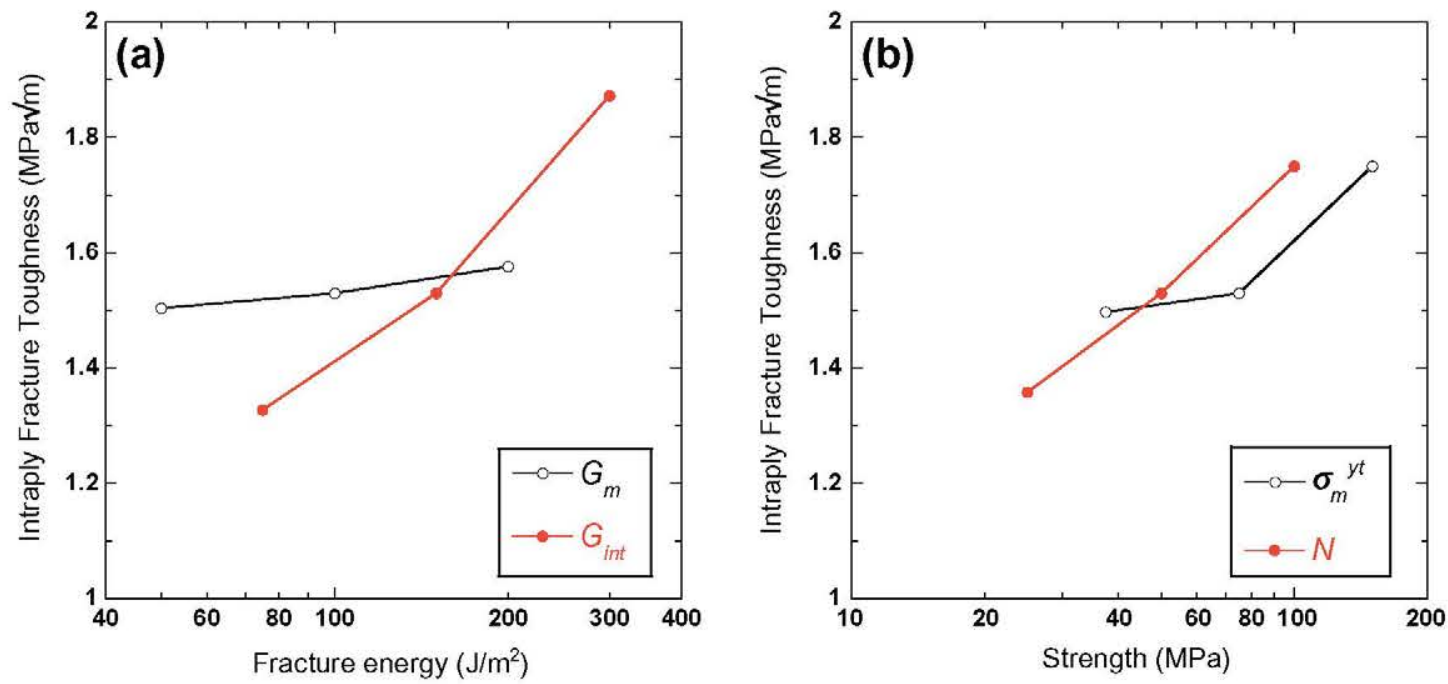

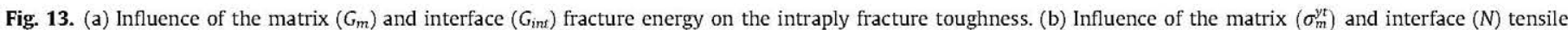
strength on the intraply fracture toughness.

approach a very interesting tool to explore the effect of the matrix and interface properties on the ply toughness. This information is important from a materials science viewpoint in order to ascertain the critical parameters to improve ply toughness but it is very difficult to obtain experimentally. Virtual tests offer another route to obtaining the answer.

Matrix, fiber and interface properties used in the previous section were taken as baseline values and a parametrical study was carried out by simulating the mechanical response of the notched beam under three-point bending for different values of the matrix strength, matrix fracture energy, interface strength and interface fracture energy. In order to limit the number of virtual tests, it was assumed that the shear-to-normal interface strength ratio $(S / N)$ and compressive-to-tensile matrix strength ratio $\left(\sigma_{m}^{y c} / \sigma_{m}^{y t}\right)$ remained constant and equal to 1.5 and 1.4 , respectively. Simulations were carried out for two different values of each parameter corresponding to one half and twice the baseline value and the corresponding results of the fracture toughness (computed from the maximum load in the virtual test using Eq. (1)) are plotted in Fig. 13a and $b$ as a function of the matrix and interface properties. Open symbols in these figures indicate the influence of interface properties while solid symbols stand for the effect of the matrix. These results indicate that a strong and tough interface is critical to enhance the intraply toughness very probably because the onset of damage is triggered by matrix/fiber decohesion in front of the notch tip (see inset in Fig. 12a). It is worth noting that both the interface strength and toughness contributed equally to enhancing intraply toughness because the initiation of decohesion depends on the former while the latter controls the propagation of the crack along the interface. The simulations also indicate that the influence of the matrix toughness on the intraply toughness is very small (Fig. 13a) while the matrix tensile strength only contributed to the intraply toughness when it was significantly higher than the interface strength (for instance, when $N=50 \mathrm{MPa}$ and $\sigma_{m}^{y t}=$ $150 \mathrm{MPa}$ ) (Fig. 13b). Otherwise, the matrix mechanical behavior played a minor role on the intraply toughness, as compared with the interface properties.

\section{Concluding remarks}

The fracture behavior parallel to the fibers and the associated fracture micromechanisms were studied in an E-glass/MTM57 unidirectional laminate. In situ tests inside the SEM showed that damage began at the notch tip as a result of fiber-matrix decohesion. Crack propagation from the notch tip was discontinuous and it was formed by a number of decohered interfaces connected by matrix ligaments. They were broken as the applied displacement increased, and a continuous crack grew from the notch.

The fracture tests were simulated by means of an embedded cell model. In this approach, the whole specimen was included in the finite element model but it was divided in two regions. The actual microstructure was represented in front of the notch tip, where all the fracture processes occur, while the remaining of the specimen was considered a homogenous solid. In addition, matrix modulus and strength were measured by means of nanoindentation tests in matrix pockets while the interface strength was obtained by push-out tests in thin slices of the composite. The numerical simulations very accurately predicted the macroscopic response of the composite as well as the damage development and crack growth in front of the notch tip, demonstrating the ability of the embedded cell approach to simulate the fracture behavior of heterogeneous materials. Finally, this methodology was exploited to ascertain the influence of the matrix and interface properties on the intraply toughness. It was found that the intraply fracture toughness was mainly dependent on the interface strength and toughness while the matrix properties played a secondary role.

\section{Acknowledgements}

This investigation was supported by the Ministerio de Ciencia e Innovación de España through the grant MAT 2009-14396, by the Comunidad de Madrid through the program ESTRUMAT (S2009/ MAT-1585), by the European Communitys Seventh Framework Programme FP7/2007-2013 under grant agreement 213371 (MAAXIMUS, www.maaximus.eu) and Sixth Framework Programme FP6 under project DEFCOM (Era-Net MATERA).

\section{References}

[1] LLorca J, González C, Molina-Aldareguía JM, Segurado J, Seltzer R, Sket F, et al. Multiscale modeling of composite materials: a roadmap towards virtual testing. Adv Mater 2011:23:5130-47.

[2] Matzenmiller A, Lubliner J, Taylor RL. A constitutive model for anisotropic damage in fiber composites. Mech Mater 1995;20:125-52.

[3] Ladevéze P, Lubineau G. On a damage mesomodel for laminates: micro-meso relationships, possibilities and limits. Compos Sci Technol 2001;61:2149-58.

[4] Maimí P, Camanho PP, Mayugo JA, Dávila CG. A continuum damage model for composite laminates: Part I constitutive model. Mech Mater 2007;39:897-908. 
[5] Nemat-Nasser S, Hori M. Micromechanics: overall properties of heterogeneous materials. North-Holland; 1999.

[6] Puck A, Schürmann H. Failure analysis of FRP laminates by means of physically based phenomenological models. Compos Sci Technol 2002;62:1633-62.

[7] Dávila C, Camanho PP, Rose CA. Failure criteria for FRP laminates. J Compos Mater 2005;39:323-45.

[8] Pinho ST, lannucci L, Robinson P. Physically-based failure models and criteria for laminated fibre-reinforced composites with emphasis on fibre-kinking. Part I: Development. Composites: Part A 2006;37:63-73

[9] González C, LLorca J. Mechanical behavior of unidirectional fiber-reinforced polymers under transverse compression: microscopic mechanisms and modeling. Compos Sci Technol 2007;67:2795-806.

[10] Totry E, González C, Llorca J. Failure locus of fiber-reinforced composites under transverse compression and out-of-plane shear. Compos Sci Technol $2008 ; 68: 829-39$.

[11] Totry E, González C, LLorca J. Influence of the loading path on the strength of fiber-reinforced composites subjected to transverse compression and shear. Int J Solids Struct 2008;45:1663-75.

[12] Canal LP. Segurado J, LLorca J. Failure surface of epoxy-modified fiberreinforced composites under transverse tension and shear. Int J Solids Struct 2009;46:2265-74.

[13] Totry E, Molina-Aldaregúia JM, González C, Llorca J. Effect of fiber, matrix and interface properties on the in-plane shear deformation of carbon-fiber reinforced composites. Compos Sci Technol 2010;70:970-80.

[14] Vaughan TJ, McCarthy CT. Micromechanical modelling of the transverse damage behaviour in fibre reinforced composites. Compos Sci Technol 2011;71:388-96

[15] Pinho ST, Robinson P, Iannucci L. Fracture toughness of the tensile and compressive fibre failure modes in laminated composites. Compos Sci Technol 2006;66:2069-79.

[16] Laffan MJ, Pinho ST, Robinson P, Iannucci L. Measurement of the in situ ply fracture toughness associated with mode I fibre tensile failure in FRP. Part I: Data reduction. Compos Sci Technol 2010;70:606-13.

[17] González C, LLorca J. Multiscale modeling of fracture in fiber-reinforced composites. Acta Mater 2006;54:4171-81.

[18] González C, LLorca J. Virtual fracture testing of fiber-reinforced composites: a computational micromechanics approach. Eng Fract Mech 2007:74:1126-38.

[19] Smilauer V, Hoover CG, Bazant ZP, Caner FC, Waas AM, Shahwan KW. Multiscale simulation of fracture of braided composites via repetitive unit cells. Eng Fract Mech 2011;78:901-18.

[20] Marshall DB. An indentation method for measuring matrix-fiber frictional stresses in ceramic composites. J Am Ceram Soc 1984;67:259-60.

[21] González C, LLorca J. Micromechanical modelling of deformation and failure in Ti-6Al-4V/SiC composites. Acta Mater 2001;49:3505-19.

[22] Zhou X-F, Wagner HD, Nutt SR. Interfacial properties of polymer composites measured by push-out and fragmentation tests. Composites: Part A $2001 ; 32: 1543-51$
23| Godara A, Gorbatikh L, Kalinka G, Warrier A, Rochez O, Mezzo L, et al. Interfacial shear strength of a glass fiber/epoxy bonding in composites modified with carbon nanotubes. Compos Sci Technol 2010;70:1346-52.

[24] Rodríguez M, Molina-Aldareguía JM, Gonzallez C, LLorca J. Determination of the mechanical properties of amorphous materials through instrumented nanoindentation. Acta Mater 2012;60:3953-64.

[25] Guinea GV, Pastor JY, Planas J, Elices M. Stress intensity factor, compliance and CMOD for a general three-point-bend beam. Int J Fract 1998;89:103-16.

[26] Molina-Aldaregúla JM, Rodríguez M, González C, LLorca J. An experimental and numerical study of the influence of local effects on the application of the fibre push-in test. Philos Mag 2011;91:1293-307.

[27] Ogihara S, Koyanagi J. Investigation of combined stress state failure criterion for glass fiber/epoxy interface by the cruciform specimen method. Compos Sc Technol 2010;70:143-50.

[28] Oliver WC, Pharr GM. An improved technique for determining hardness and elastic modulus using load and displacement sensing indentation experiments. J Mater Res 1992;7:1564-83.

[29] Cheng YT, Cheng CM. Scaling, dimensional analysis and indentation measurements. Mater Sci Eng R 2004;44:91-149.

[30] Canal LP, Experimental and computational micromechanical study of fiber reinforced polymers. Ph.D. thesis, Polytechnic University of Madrid; 2011.

[31] Quinson R, Perez J, Rink M, Pavan A. Yield criteria for amorphous glassy polymers. J Mater Sci 1997;32:1371-9.

[32] Benveniste Y. A new approach to the application of Mori-Tanaka's theory in composite materials. Mech Mater 1987;6:147-57.

[33] Lubliner J, Oliver J, Oller S, Oñate E. A plastic-damage model for concrete. Int J Solids Struct 1989;25:299-329.

[34] Lee J, Fenves GL. Plastic-damage for cyclic loading of concrete structures. J Eng Mech 1998;124:892-900.

[35] Bažant ZP, Oh BH. Crack band theory for fracture of concrete. Mater Struct $1983 ; 16: 155-77$.

[36] Abaqus. Analysis user's manual, version 6.10. Simulia; 2011.

37] Paul DR, Bucknall CB. Polymer Blends. Performance, vol. 2. Wiley-interscience; 2000.

[38] Sket F, Seltzer R, Molina-Aldaregúa JM, González C, LLorca J. Determination of damage micromechanisms and fracture resistance of glass fiber/epoxy crossply laminate by means of X-ray computed microtomography. Compos Sci Technol 2012;72:350-9.

[39] Camanho P, Dávila CG. Mixed-mode decohesion finite elements for the simulation of delamination in composite materials. NASA/TM-2002-211737; 2002.

[40] Totry E, González C, Llorca J, Molina-Aldaregúra JM. Mechanisms of shear deformation in fiber-reinforced polymers: experiments and simulations. Int Fract 2009;158:197-209. 